\title{
Factors Correlated with Relapse among Substance Abuse Patients
}

\author{
Mona Hassan Abdel Aal. Fatma Atta \\ Psychiatric Mental Health Nursing, Faculty of Nursing- Ain Shams University
}

\begin{abstract}
Background: Substance abuse is a chronic and relapsing disorder with different genetic, mental, social and environmental factors, influencing its commencement and continuation. Aim: The study aimed to assess factors correlated with relapse among substance abuse patients. Setting: The present study carried out at institute of psychiatry affiliated to Ain Shams university hospitals and El Khanka Hospital Sample: A convenient sample of 120 relapse patients from institute of psychiatry and El Khanka Hospital. Tools of data collection:: Structured questionnaire was utilized. It included two parts. Part I: to assess socio-demographic characteristics. Part 2: Questionnaire about factors correlated with relapse among substance abuse patients Results: It was founded that relapse dimensions represented from the greatest to the lowest mean score as the following; Unpleasant feelings, good feelings, disruption of relationships with others, mental, physical and debilitating pains, desire and real estate hints, test the ability to control the abuse, the pressure of the co-workers, and the least of them for Family problems Conclusion: It was concluded that, there was a significant positive correlation between all dimensions of relapse and socio-demographic characteristics as age, place of birth, level of education and economic status. Recommendation: Developing future prevention programs for protection against substance abuse.
\end{abstract}

Key words: Factors- Relapse - Substance Abuse Patients

Introduction

Substance abuse is a chronic and relapsing disorder, with different genetic, mental, social and environmental factors influencing its commencement and continuation. Substance abuse relapse is a universal phenomenon and the central problem in treatment of addictive behaviors. It mostly affects the offspring's life and places severe burdens on advantages and productive group of young people. Abolhasan, et al (2016). Substance abuse is related disorders that involve maladaptive pattern of substance use leading to significant impairment in functioning, it is not a character flaw but rather a medical condition that has developed over time, Sampson, et al (2017).

Addiction is a primary, chronic disease of brain reward, motivation, memory and the related circuitry Abolhasan, et al (2016). Addiction is a major problem in Egypt, due to rapidly growing and changing patterns of substance use. In Egypt Addiction represents $10 \%$ of total population. The highest governorates of addiction in Egypt are ElQahra, Sohage, and the least ElMonefia. Substance use disorders occur when an 
individual continues using substances despite cognitive, behavioral, and physiological symptoms, Hamdi et al (2013). The Egyptian census in 2015 was 87,963,276 people, a study revealed that about one fifth $(\mathbf{1 9 . 1 \%})$ of the studied sample are regularly using substance (tobacco smoking was excluded) Hamdi et al (2016).

Relapse word is taken from the Latin word Relapi , that means fall or sliding back into former bad or viscous state or practices, especially into illness after partial recovery. It can be defined as the process of recurrence of alcohol or drug dependency behaviors in an individual who have previously achieved and maintained abstinence for a significant time beyond the period of detoxification, Relapse as a setback that occurs during the behavior change process, such that progress toward the initiation or maintenance of a behavior change goal (e.g., abstinence from drug use) is interrupted by a reversion to the target behavior. Mohammed, (2009).

In this respect, Anil, et al (2008) defined relapse as an unfolding process in which the resumption of substance uses is the last event in a long sequence of maladaptive responses to internal or external stressors and stimuli.

The prevalence of chemical dependence relapse among substance abusers had been estimated to be $75-90 \%$ within the first year of release from treatment Iqbal (2008). Added to that, correlated with relapse are; urge, craving, and drug temptation, negative or positive emotional state, negative physical state, testing of personal control, family or others relationship conflicts, social and peer pressures to use substances, and treatment related barriers. (Mohammed 2009).

There are considerable regional variations in the overall rates of substance use/abuse in Egypt. However, the demographic risk factors are remarkably consistent across regions with only minor differences. Substance use and abuse have higher lifetime prevalence among young and middle aged males, less educated persons, working in technical or commercial jobs, with failed marriage, and living in urban areas (Hamdi et al 2016).

\section{Significance of the Study}

Drug abuse is a disorder associated with an unhealthy pattern of drug consumption, and causes social problems for the individual. These problems include the lack of responsibility in the home, workplace and school or even legal problems for the individual. It imposes a serious damage on the societies that could be social, economic, political, cultural or related to health. Health damages like hepatitis and AIDS can be transmitted by injecting drugs. It also results in socio-cultural damages like increased addiction-induced crimes such as theft, murder, self-immolation, joblessness, family rudeness, child abuse, increased separations, and the educational failure of students with addiction .

Psychiatric mental health nurse has a crucial role in preventing and management of relapse through helping the patients and their families to develop positive coping strategies against factors correlated with relapse among substance abuse, such as enhancing the patients' feelings of life mastery and prepare the patient for healthier life style with lifelong abstinence.

\section{Aim of the study:}

The study aimed to assess factors correlated with relapse among substance abuse patients.

\section{The aim will be achieved through:}

Assessing factors that correlated with relapse.

Assessing correlation between dimensions of relapse. 


\section{Subjects and Methods}

\section{Research Question:}

What are the factors that correlated with relapse among substance abuse patients?

Subjects and methods of this study were portrayed under four main designs as following:

I. Technical design. II. Operational design. III. Administrative design. IV. Statistical design

\section{I- Technical Design:}

It included the research design, study setting, subjects and tools of data collection.

\section{Research design:}

A descriptive correlational research design was adopted to fulfill the purpose of this study, that assessing factors correlated with relapse among substance abuse patients.

\section{Research setting:}

The present study was carried out at outpatient clinic at institute of psychiatry affiliated to Ain Shams university hospitals and outpatient clinic at El khanka hospital (governmental hospital).

\section{Subjects:}

\section{A-Sampling technique:}

Selection of the sample contained type , size and criteria of the sample.

\section{A-Sample type}

A convenient sample of substance abuse relapse patients were included in the study.

\section{B- Sample size}

From total of patients attending outpatient clinic at institute of psychiatry affiliated to Ain Shams university hospitals and outpatient clinic at El khanka hospital(governmental hospital), the required sample obtained $(n=120)$. Institute of psychiatry (70), El khanka hospital(governmental hospital) (50). According to sample equation a convenient sample of patients with substance abuse relapses was selected:

$$
\begin{aligned}
& \mathrm{n}=\frac{\mathrm{N} \times \mathrm{P}(1-\mathrm{P})}{\left[\left[\mathrm{N}-1 \times\left(d^{2} \div \mathrm{Z}^{2}\right)\right]+(1-\mathrm{P}) \mathrm{P}\right]} \\
& \mathrm{n}=\text { sample size } \\
& \mathrm{N}=\text { population size }
\end{aligned}
$$

$\mathrm{Z}=$ standard score corresponding to the level of significance equal to 0.95

$$
\text { and } 1.96
$$

$\mathrm{d}=$ the error rate is equal to 0.05

$\mathrm{P}=$ ratio provides a neutral property 0.5 .

\section{C-Inclusion criteria:}

- $\quad$ Age $15->45$

- $\quad$ Agree to participate

- Previous history of substance abuse

- Previous history of relapse

\section{Study variables:}

\section{Dependent variable: Relapse}

Independent variables: Sociodemographic variables (age, social status, place of live, level of education, occupation, and economic status) 


\section{Tools of data collection:-}

Arabic questionnaire was utilized in this study. It includes the following variables:

\section{Part I: Structured Interview} Questionnaire to assess:

Sociodeographic characteristics of patients, as age, place of residence, hospital name, marital status, education, economic status.

Part II: Questionnaire about factors correlated with relapse among substance abusers, adapted from Abdel Karim et al (2010), which adopted from Askar \& El Didi (2005), it included eight dimensions including 100 questions for assessing relapse as the following; (Dimension 1); Desire and Real Estate Hints (15 items), as; when I remembered her taste, ...ect (Dimension 2); Test the Ability to Control the Abuse, (9 items), as; when I convinced myself that I was a new person I could be used to abuse, ...ect (Dimension 3), Pressure from the coworkers, (7 items), as; when I was with my friends and I was determined to deal with them, ...ect (Dimension 4); Good Feelings, (18 items), as when I felt confident and calm, ...ect (Dimension 5); Unpleasant Feelings, (18 items), as when I felt I was less than anyone else...ect (Dimension 6); Disruption of Relationships with Others, (15 items), as when I disagreed with my friend, because I felt people did not like me, ...ect (Dimension 7); Family Problems, (5 items), as when there were fights at home...ect (Dimension 8); Mental, Physical and Debilitating Pains (13 items), as when I felt the difficulty of sleep, ...ect Scoring System:

To measure factors correlated with relapse which are eight dimensions; desire and real estate hints, inability to control the abuse, pressure from the co-workers, good feelings situations, unpleasant feelings, disruption of relationships with others, family problems, mental, physical and debilitating pains. The answers of the questions are rated as the following:

Applicable scored as ---------2

Not applicable scored as --------1

Total score from 1-100 means Not Applicable. However the score ranged from 101-200 means applicable.

\section{Tool Reliability:}

The Chronbach alpha test was used to measure the internal consistency of questionnaire with eight dimensions concerned with factors correlate to relapse that represented in the following table as the following

\begin{tabular}{|l|c|}
\hline Dimensions of Relapse & Chronbach Alpha \\
\hline Dimension1 & 0.90 \\
\hline Dimension2 & 0.86 \\
\hline Dimension3 & 0.84 \\
\hline Dimension4 & 0.95 \\
\hline Dimension5 & 0.95 \\
\hline Dimension6 & 0.92 \\
\hline Dimension7 & 0.89 \\
\hline Dimension8 & 0.94 \\
\hline Total & $\mathbf{0 . 9 8}$ \\
\hline
\end{tabular}

\section{Operational Design:}

The operational design for this study included preparatory phase, pilot study, validity and reliability, ethical considerations, fieldwork, and limitations of the study.

\section{A-Preparatory phase:}

It included reviewing past, current, local and international related literature and theoretical knowledge of substance abuse, relapse, factors correlated with relapse using books, articles, internet, and periodicals to get acquainted with the research problem and to prepare the study tools. 


\section{Tools validity:}

Validity test was used at this stage: face and content validity: Face validity aimed at inspecting the items to determine whether the tools measure what is supposed to measure. Content validity was conducted to determine whether the tools cover the appropriate and necessary content as well as its relevance to the tools and the study aim.

A jury experts group consisted of three university academic staff; all of them were professors and assistant professors from departments of psychiatry, and public health nursing at Faculty of Nursing -Ain Shams University.

The experts' opinions were asked to respond to each statement of the development assessment and evaluations tools as "agree or disagree" or "agree with modification".

\section{Pilot study:}

A pilot study had been done on a sample of $10 \%$ of subjects with relapse (12) at outpatient clinics of two hospitals (institute of psychiatry Affiliated to Ain Shams University Hospitals (7) and El Khanka hospital (5)). Before embarking in the field of work to ascertain the clarity and applicability in the study tool and to identify the time needed for each subject interview and availability of the sample. The necessary modifications done to develop the final format.

\section{Field Work:}

\section{Data Collection Procedure:}

The study started at May 2017, once the permission was granted to conduct the study, the researchers started to collect the data. The researchers introduced themselves and explained the purpose of the study to each substance abuse relapse patient. Oral consent took from patients. The confidentiality of any obtained information was assured, and the patients were informed about their right to participate or not in the study. Each participant was interviewed personally in the outpatient clinic at each hospital for about 25-40 minutes. Data collection for this study was carried out in about three months from May 2017 to July 2017. Data was collected from subjects two days days/week, attendance exchange between the researchers per week at institute of psychiatry Affiliated to Ain Shams University Hospitals and El Khanka hospital.

\section{Administrative approval:}

An official approval obtained from Dean of Faculty of Nursing - Ain Shams University to the director of afro mentioned settings (institute of psychiatry Affiliated to Ain Shams University Hospitals and El Khanka hospital). To facilitate the mission of collecting the study data. Patient's consent to participate in this study was obtained.

\section{Ethical consideration:}

All patients were informed that participation in the study is voluntary. Anonymity and confidentiality of each patient will be respected and protected. All patients were informed that the content of the tool will be used for research purpose only and they have the right to participate in the study or withdrawal at any time.

\section{Statistical Design:}

\section{Data analysis:}

Data analysis was done by using the SPSS-version 21.

Description of the data in form of mean $\pm \mathrm{SD}$ for quantitative variables as well as frequency and percentages for qualitative variables were performed. The level of significance will be taken at 0.05 . 
Results:

Table (1) shows that sociodemographic characteristics represented as following;

About $58.4 \%(29.2 \%+29.2 \%)$ of the study subjects fall between $25-<45$ years old, With $50 \%$ of them were single, 62.5 of them with $3-5$ family number, $70.8 \%$ live in city, with $25.0 \%+38.3 \%$ of study sample having average education, $55.8 \%$ with no occupation and $54.2 \%$ of them had average economic status.

Regarding History of Behavior Associated and Treatment among Substance Abuse appeared in Table (2), that subjects who are smoking represented $89.2 \%$, smoking represented narghile $41.7 \%$ and $12.5 \%$ of them jailed for drugs. $52.5 \%$ of the study subjects started using drugs at age of $15-<25$ years old, added to that $33.3 \%$ of the sample last for $5-<10$ number of years of addiction before treatment, and $33.3 \%$ of them their duration of treatment within the center was from one year - > 3 years. The Longer weaning duration for drug after treatment, represented $79.2 \%$ of them between $1->5$ years. While $66.7 \%$ of them having relapse, and lastly $65.0 \%$ of study sample forced by others for treatment.

As shown in figure ( 1) types of narcotics taken during years of addiction as the following, Alcohol, Sleeping Pills, Mariguana, Hashish, Stimulating Pills, Soothing Pills, Codeine, Hallucination Pills, Cocaine, Morphine, Heroin, Crystal, Opium, Crack, then Ecstasy Pills were representing; 75\%, 69.2\%, 62.5\%, 52.5\%,
$50 \%, 43.3 \%, 29.2 \%, 24.2 \%, 24.2 \%, 21.7 \%$, $17.5 \%, 15.8 \%, 14.2 \%, 12.5 \%$, then $11.7 \%$ sequentially.

Concerning mean score for dimensions of relapse among substance abuse patients, that illustrated in table (3). It was found that relapse dimensions represented from the greatest to the lowest mean score as the following; unpleasant feelings, good feelings, disruption of relationships with others, mental, physical and debilitating pains, desire and real estate hints, test the ability to control the abuse, the pressure of the co-workers, and the least for family problems, which estimated as the following; $27.01 \pm 7.36$, $24.37 \pm 6.8, \quad 21.84 \pm 6.32, \quad 18.71 \pm 5.2$, $16.02 \pm 4.48, \quad 13.5 \pm 3.82, \quad 9.36 \pm 2.81$, and finally $6.66 \pm 2.07$.

Table, 4 reveals correlations between socio-demographic characteristics and dimensions of relapse among substance abuse patients, shown that there were highly significant positive correlation between all dimensions of relapse and age, place of birth, level of education and economic status.

Correlations between history of behavior associated and treatment among substance abuse patients, and dimensions of relapse were illustrated in table 5, which reveals highly significant positive correlations between all dimensions of relapse and smoking Narghile, age at starting using Drugs, years of Addiction before treatment, duration of treatment within the center, longer weaning duration for drug after treatment, number of relapses and times of therapy by patient decision. 
Table (1) Socio-demographic Characteristics of the Study Subjects n=120

\begin{tabular}{|c|c|c|}
\hline Socio-demographic Characteristics & $\mathrm{N}$ & $\%$ \\
\hline \multicolumn{3}{|l|}{ Age } \\
\hline $15-<25$ & 40 & 33.3 \\
\hline $25-<35$ & 35 & 29.2 \\
\hline $35-<45$ & 35 & 29.2 \\
\hline $\begin{array}{c}\text { Mean } \pm \text { SD } \\
2.1250 \pm .97500\end{array}$ & 10 & 8.3 \\
\hline $\begin{array}{l}\text { Hospital } \\
\text { El Khanka } \\
\text { Institute of Psychiatry }\end{array}$ & $\begin{array}{l}50 \\
70\end{array}$ & $\begin{array}{l}41.7 \\
58.3\end{array}$ \\
\hline \multicolumn{3}{|l|}{ Social Status } \\
\hline Single & 60 & 50.0 \\
\hline Married & 50 & 41.7 \\
\hline Divorced & 10 & 8.3 \\
\hline Separated & 0 & 0 \\
\hline \multicolumn{3}{|l|}{ Family Number } \\
\hline $3-5$ & 75 & 62.5 \\
\hline $6-8$ & 45 & 37.5 \\
\hline \multicolumn{3}{|l|}{ Place of live } \\
\hline City & 85 & 70.8 \\
\hline Village & 35 & 29.2 \\
\hline \multicolumn{3}{|l|}{ Level of Education } \\
\hline Primary & 15 & 12.5 \\
\hline Preparatory & 20 & 16.7 \\
\hline Secondary & 30 & 25.0 \\
\hline Diplom after prep school & 46 & 38.3 \\
\hline University \& post graduate & 9 & 7.5 \\
\hline \multicolumn{3}{|l|}{ Occupation } \\
\hline Yes & 53 & 44.2 \\
\hline No & 67 & 55.8 \\
\hline \multicolumn{3}{|l|}{ Economic Status } \\
\hline Very satisfactory & 7 & 5.8 \\
\hline Satisfactory & 30 & 25.0 \\
\hline Average & 65 & 54.2 \\
\hline Difficult & 18 & 15.0 \\
\hline
\end{tabular}


Table (2) History of Behavior Associated and Treatment among Substance Abuse Patients n=120

\begin{tabular}{|c|c|c|}
\hline History of Behavior Associated and Treatment & $\mathrm{N}$ & $\%$ \\
\hline \multicolumn{3}{|l|}{ Do you smoke cigarettes } \\
\hline Yes & 107 & 89.2 \\
\hline No & 13 & 10.8 \\
\hline \multicolumn{3}{|l|}{ Do you smoke narghile } \\
\hline Yes & 50 & 41.7 \\
\hline No & 70 & 58.3 \\
\hline \multicolumn{3}{|l|}{ jailed for drugs } \\
\hline Yes & 15 & 12.5 \\
\hline No & 105 & 87.5 \\
\hline \multicolumn{3}{|l|}{ The age at which you started using drugs } \\
\hline$(15->25)$ & 63 & 52.5 \\
\hline$(25->35)$ & 43 & 35.8 \\
\hline $35+$ & 14 & 11.7 \\
\hline \multicolumn{3}{|l|}{ Number of years of addiction before treatment } \\
\hline$\left(\begin{array}{ll}1 & ->5\end{array}\right)$ & 50 & 41.7 \\
\hline$(5->10)$ & 40 & 33.3 \\
\hline$(10->15)$ & 23 & 19.2 \\
\hline $15+$ & 7 & 5.8 \\
\hline \multicolumn{3}{|l|}{ Duration of treatment within the center } \\
\hline One month $->6$ months & 35 & 29.2 \\
\hline 6 months $->12$ months & 30 & 25.0 \\
\hline One year $->3$ years & 40 & 33.3 \\
\hline 3 years + & 15 & 12.5 \\
\hline \multicolumn{3}{|c|}{ Longer weaning duration for drug after treatment } \\
\hline$(1->5)$ & 95 & 79.2 \\
\hline$(5-10)$ & 25 & 20.8 \\
\hline \multicolumn{3}{|c|}{ Number of relapses (return to drug use after hygiene) } \\
\hline Yes & 80 & 66.7 \\
\hline No & 40 & 33.3 \\
\hline \multicolumn{3}{|c|}{ In previous times, do you went to therapy on your own? } \\
\hline Yes & 42 & 35.0 \\
\hline No & 78 & 65.0 \\
\hline
\end{tabular}




\section{Types of Narcotics}

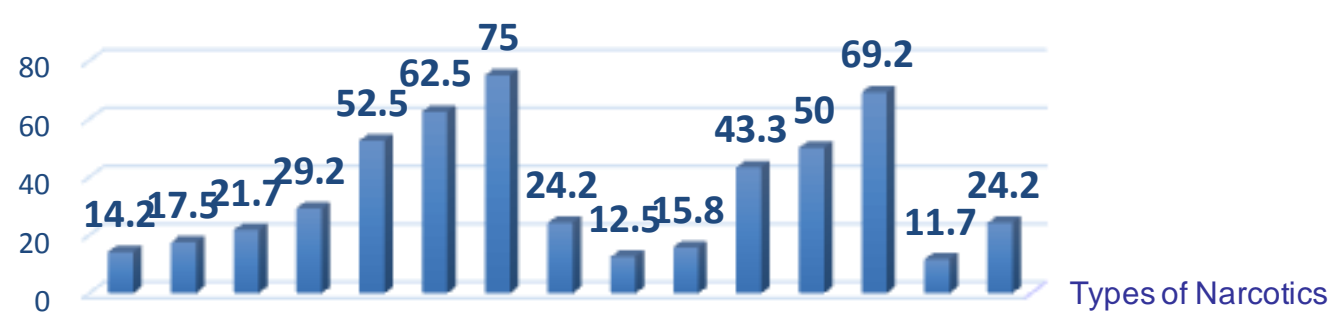

Types of Narcotics

Figure ( 1 ) Types of Narcotics Taken during Years of Addiction

Table (3 ) Mean Score for Dimensions of Relapse among Substance Abuse Patients n=120

\begin{tabular}{|c|c|}
\hline Dimensions of Relapse & Means \pm SD \\
\hline 1. Desire and real estate hints & $16.02 \pm 4.48$ \\
\hline 2. Test the ability to control the abuse & $13.5 \pm 3.82$ \\
\hline 3. The pressure of the co-workers & $9.36 \pm 2.81$ \\
\hline 4. Good feelings & $24.37 \pm 6.8$ \\
\hline 5. Unpleasant feelings & $27.01 \pm 7.36$ \\
\hline 6. Disruption of relationships with others & $21.84 \pm 6.32$ \\
\hline 7. Family problems & $6.66 \pm 2.07$ \\
\hline 8. Mental, physical and debilitating pains & $18.71 \pm 5.2$ \\
\hline
\end{tabular}


Table (4) Correlations between Sociodemographic Characteristics and Dimensions of Relapse among Substance Abuse Patients n=120

\begin{tabular}{|c|c|c|c|c|c|}
\hline Dimensions of Relapse & $\mathbf{r}$ & Age & $\begin{array}{l}\text { Place of } \\
\text { live }\end{array}$ & $\begin{array}{l}\text { Level of } \\
\text { education }\end{array}$ & $\begin{array}{c}\text { Economic } \\
\text { Status }\end{array}$ \\
\hline \multirow[t]{2}{*}{ Desire and real estate hints } & $\mathbf{r}$ & .948 & .820 & .883 & .794 \\
\hline & $P$ value & .000 & .000 & .000 & .000 \\
\hline \multirow{2}{*}{$\begin{array}{l}\text { Test the ability to control the } \\
\text { abuse }\end{array}$} & $\mathbf{r}$ & .941 & .758 & .897 & .797 \\
\hline & $P$ value & .000 & .000 & .000 & .000 \\
\hline \multirow{2}{*}{$\begin{array}{l}\text { The pressure of the co- } \\
\text { workers }\end{array}$} & $\mathbf{r}$ & .900 & .892 & .798 & .725 \\
\hline & P value & .000 & .000 & .000 & .000 \\
\hline \multirow[t]{2}{*}{ Good feelings } & $\mathbf{r}$ & .926 & .888 & .840 & .769 \\
\hline & $P$ value & .000 & .000 & .000 & .000 \\
\hline \multirow[t]{2}{*}{ Unpleasant feelings } & $\mathbf{r}$ & .945 & .765 & .914 & .823 \\
\hline & $P$ value & .000 & .000 & .000 & .000 \\
\hline \multirow{2}{*}{$\begin{array}{l}\text { Disruption of relationships } \\
\text { with others }\end{array}$} & $\mathbf{r}$ & .922 & .807 & .876 & .773 \\
\hline & $P$ value & .000 & .000 & .000 & .000 \\
\hline \multirow[t]{2}{*}{ Family problems } & $\mathbf{r}$ & .870 & .948 & .754 & .703 \\
\hline & $P$ value & .000 & .000 & .000 & .000 \\
\hline \multirow{2}{*}{$\begin{array}{l}\text { Mental, physical and } \\
\text { debilitating pains }\end{array}$} & $\mathbf{r}$ & .942 & .792 & .890 & .801 \\
\hline & $P$ value & .000 & .000 & .000 & .000 \\
\hline
\end{tabular}


Table (5) Correlations between History of Behavior Associated and Treatment and dimensions of relapse among Substance Abuse Patients $\mathbf{n}=120$

\begin{tabular}{|c|c|c|c|c|c|c|c|c|}
\hline $\begin{array}{l}\text { Dimensions } \\
\text { of Relapse }\end{array}$ & $\mathbf{r}$ & $\begin{array}{l}\text { smoking } \\
\text { narghile }\end{array}$ & $\begin{array}{c}\text { age at } \\
\text { starting } \\
\text { using } \\
\text { drugs }\end{array}$ & $\begin{array}{c}\text { years of } \\
\text { addiction } \\
\text { before } \\
\text { treatment }\end{array}$ & $\begin{array}{c}\text { Duration } \\
\text { of } \\
\text { treatment } \\
\text { within } \\
\text { the } \\
\text { center }\end{array}$ & $\begin{array}{c}\text { Longer } \\
\text { weaning } \\
\text { duration } \\
\text { for drug } \\
\text { after } \\
\text { treatment }\end{array}$ & $\begin{array}{c}\text { Number } \\
\text { of } \\
\text { relapses }\end{array}$ & $\begin{array}{c}\text { times, } \\
\text { of } \\
\text { therapy } \\
\text { by } \\
\text { patient } \\
\text { decision }\end{array}$ \\
\hline \multirow{2}{*}{$\begin{array}{l}\text { Desire and } \\
\text { real estate } \\
\text { hints }\end{array}$} & $\mathbf{r}$ & .846 & .905 & .906 & .935 & .688 & .877 & .793 \\
\hline & $\begin{array}{c}\mathbf{P} \\
\text { value }\end{array}$ & .000 & .000 & .000 & .000 & .000 & .000 & .000 \\
\hline \multirow{2}{*}{$\begin{array}{l}\text { Test the } \\
\text { ability to } \\
\text { control the } \\
\text { abuse }\end{array}$} & $\mathbf{r}$ & .883 & .872 & .878 & .930 & .606 & .836 & .849 \\
\hline & $\begin{array}{c}\mathbf{P} \\
\text { value }\end{array}$ & .000 & .000 & .000 & .000 & .000 & .000 & .000 \\
\hline \multirow{2}{*}{$\begin{array}{l}\text { The } \\
\text { pressure of } \\
\text { the co- } \\
\text { workers }\end{array}$} & $\mathbf{r}$ & .715 & .916 & .895 & 882 & .791 & .918 & .621 \\
\hline & $\begin{array}{c}P \\
\text { value }\end{array}$ & .000 & .000 & .000 & .000 & .000 & .000 & .000 \\
\hline \multirow{2}{*}{$\begin{array}{l}\text { Good } \\
\text { feelings }\end{array}$} & $\mathbf{r}$ & .778 & .931 & .936 & .914 & .793 & .906 & .691 \\
\hline & $\begin{array}{c}\mathbf{P} \\
\text { value }\end{array}$ & .000 & .000 & .000 & .000 & .000 & .000 & .000 \\
\hline \multirow{2}{*}{$\begin{array}{l}\text { Unpleasant } \\
\text { feelings }\end{array}$} & $\mathbf{r}$ & .889 & .872 & .891 & .946 & .629 & .824 & .852 \\
\hline & $\begin{array}{c}P \\
\text { value }\end{array}$ & .000 & .000 & .000 & .000 & .000 & .000 & .000 \\
\hline \multirow{2}{*}{$\begin{array}{l}\text { Disruption } \\
\text { of } \\
\text { relationships } \\
\text { with others }\end{array}$} & $\mathbf{r}$ & .880 & .898 & .910 & .924 & .664 & .848 & .794 \\
\hline & $\begin{array}{c}\mathbf{P} \\
\text { value }\end{array}$ & .000 & .000 & .000 & .000 & .000 & .000 & .000 \\
\hline \multirow{2}{*}{$\begin{array}{l}\text { Family } \\
\text { problems }\end{array}$} & $\mathbf{r}$ & .683 & .866 & .899 & .835 & .829 & .945 & .593 \\
\hline & $\begin{array}{c}\mathbf{P} \\
\text { value }\end{array}$ & .000 & .000 & .000 & .000 & .000 & .000 & .000 \\
\hline \multirow{2}{*}{$\begin{array}{l}\text { Mental, } \\
\text { physical and } \\
\text { debilitating } \\
\text { pains }\end{array}$} & $\mathbf{r}$ & .854 & .917 & .900 & .942 & .677 & .853 & .796 \\
\hline & $\begin{array}{c}\mathbf{P} \\
\text { value }\end{array}$ & .000 & .000 & .000 & .000 & .000 & .000 & .000 \\
\hline
\end{tabular}


Discussion

Regarding history of behavior associated and treatment among substance abuse. The results cleared that subjects who are smoking represented approximately most of the study sample. Less than half of the sample was smoking Narghile and $12.5 \%$ of them jailed for drugs. More than half of the study subjects started using drugs at age of $15-<25$ years old, added to that one third of the sample last for $5-<10$ number of years of addiction before treatment, and one third of them their duration of treatment within the center was from one year $->3$ years. The Longer weaning duration for drug after treatment, represented nearly the majority of them between $1 \rightarrow 5$ years. While more than two third of them having relapse, and lastly less than two third of study sample forced by others for treatment. The results findings were supported by Iqbal (2009), who stated that half of respondents had treatment at least once before the last relapse whereas 7 respondents $(16 \%)$ indicated that they went twice and $3(7 \%)$ went more than three times for treatment. In $27 \%$ of the responses, this was the first time that respondents went for treatment.

In the treatment of substance dependency, research has found that the proportion of cases who were relapsed at least once during a year after treatment may be as high as $90 \%$ Connors et al., (1996). These findings were consistent with the views held by researchers Strowig (2000) who found that individuals may enter a treatment facility more than once following a relapse.

Three quarters of the subjects were taking Alcohol, about more than half were taking sleeping pills and Mariguana, and nearly half of the subjects were taking Hashish and stimulating pills. However, small numbers of them were taking Crack and Ecstasy pills. The current result is disagreement with the study was conducted by Mohamed (2009) who found that most of substance abusers in the Middle East abuse cannabis (marijuana, hashish) that is socially accepted more than heroin, alcohol or other substances as a non addictive, not a prohibited substance and easily obtained than other substances.

This result is partially consistent with McPherson et, al., (2017) who reported that Drug use rates in Canada as Alcohol is the most commonly used Drug, with $80 \%$ of adults reporting its use in the past year, compared to $8.4 \%$ using cannabis, $0.7 \%$ using cocaine/ crack, and $0.4 \%$ using hallucinogens. In another study by Hamdi etal (2016) in Egypt, it was found that, Cannabis was the commonest in all regions. In total,77\% of the substance users were using Cannabis. Alcohol (28.6\%of total use) was the 2nd common substance of use in all Egyptian governorates, except in Upper Egypt (where the opiates were commoner than alcohol). Meanwhile, in governorates outside the Upper Egypt, opiates were the 3rd common substance of use in Egypt (23.4\% of total use).The pharmacological agents $(14.6 \%)$, the stimulants $(1.9 \%)$ and the organic solvents $(1.5 \%)$ are following in frequency, respectively.

Concerning mean score for dimensions of relapse among substance abuse patients, it was found that relapse dimensions represented from the greatest to the lowest mean score as the following; unpleasant feelings, good feelings, disruption of relationships with others, mental, physical and debilitating pains, desire and real estate hints, test the ability to control the abuse, the pressure of the co-workers, and the least for family problems, which estimated as the following; $\quad 27.01 \quad \pm 7.36, \quad 24.37 \pm 6.8$, $21.84 \pm 6.32, \quad 18.71 \pm 5.2, \quad 16.02 \pm 4.48$, $13.5 \pm 3.82,9.36 \pm 2.81$, and finally $6.66 \pm 2.07$. This could be explained by that when the respondents were confronted with the highrisk situation, post treatment and following a period of abstinence, and for example experienced a negative emotional state namely anger or frustration, the respondent 
failed to exhibit effective coping skills and the resultant led to the initial lapse.

The above results were partially consistent with research done by Zywiak et al. (1996) as their results indicated that the predominant factor was negative emotions from both the intrapersonal and interpersonal domains, followed by social pressure and lastly wanting to get high, testing control, substance cues and urges to drink. These findings were also consistent with the negative emotional states as characteristic that the person experiences prior to relapse. The experience of negative-emotional states and exposure to social pressure constitute high-risk situations for relapse to alcohol and substance use.

Moreover the findings were partially consistent with research by Broome et al. (2002) who found that the social context can serve either as a resource or an obstacle for behavior change by the patient post treatment. For example; Negative peer influences have been noted in the development of substance use behavior and the promotion of relapse. Ibrahim \& Kumar, (2009) \& Chang et al (2016).

As mentioned by Perkinson (2004) who mentioned that when a person is poorly socialized into the culture, or if the culture makes the substance the recreational Drug of choice, it is difficult for the patient to maintain sobriety.

This is consistent with Marlatt, (1996) that abstinence violation effect where he hypothesized that if a person experienced conflict, guilt and or self-blame regarding an initial lapse this would lead the person to drink even more. He added that the negative emotions of anger, frustration, sadness and anxiety could also be present making future lapses more likely.

As noted in Wechsberg (2012) the co-occurrence of mental illness with substance abuse was evaluated to be indicative of relapse and re-admission.

According to Beuster and Arnott ( 2007) patients with serious health problems might be more motivated to seek treatment for their dependency on alcohol.

The current study showed that there were significant positive correlations between all dimensions of relapse and age, place of birth, level of education and economic status showed. This result was agree with Rimaz et, al., (2013) who explain that, the financial poverty, life costs and bankruptcy have a remarkable influence on the relapse of addiction, wealth can serve as an influential factor on the relapse of addiction.

The high rates at which individuals return to substance after abstaining for a period of time supports the views held by counselors and clients that although it is difficult for a client to give up his/her dependency to substances it is even more difficult to remain abstinent Marlatt \& Witkiewitz, (2007). These findings are consistent with the views held by researchers Strowig, (2000), that individuals may enter a treatment facility more than once following a relapse. In contrast, Amit et al., (2012) mentioned that, unemployment, peer pressure, family and social stresses were factors that showed statistical significant associations with repeat admissions.

In this respect, Broome et al. (2002) reported that the social context can serve either as a resource or an obstacle for behavior change by the patient post treatment. For example, negative peer influences have been noted in the development of substance use behavior and the promotion of relapse" Ibrahim \& Kumar, (2009).

As mentioned by Perkinson (2004) when an individual is ignorant of healthy Alcohol use and is susceptible to heavily 
using peers, abuse of substances may increase. He also mentioned, further that when a person is poorly socialized into the culture, or if the culture makes the substance is the recreational drug of choice, it is difficult for the patient to maintain sobriety.

\section{Conclusion}

The study revealed that, there were significant positive correlation between all dimensions of relapse (desire and real estate hints, inability to control the abuse, pressure from the co-workers, good feelings situations, unpleasant feelings, disruption of relationships with others, family problems, mental, physical and debilitating pains) and age, place of birth, level of education and economic status.

\section{Recommendations}

- Reinforce the role of Clergy Moslem and Christian in advice about prohibit of addiction, and empowering moral values and ethics.

- Raising awareness about importance of early engagement of children in different activities like practicing sports to ventilate their energy that protect them in adolescent period against addiction.

- Raising awareness about protection against unemployment as it is cause and effect of addiction and raising the value of work.

- Assertiveness program for each education category to know how to say No for addiction

- Adding to curriculums of education category, lessons about how addiction devastate persons, families, communities.
- $\quad$ Raising awareness of policy makers to the importance of detecting the actual status of substance abuse problems, and the significance of developing future prevention programs for protection against Addiction through mass media.

\section{References}

Abdel Karim, A. Abdalla, T. Elhalak, E. Elgendy, N. (2010) Relapse degree among sample of drug ex-addicts and addicts. Master Thesis, Jerusalem University, Palestine.

Abolhasan Afkar,1,2 Seyed Mahmoud Rezvani,3 and Abdolhosein Emami Sigaroudi (2016) Measurement of Factors Influencing the Relapse of Addiction: A

Amit. K. Sharma; Suneet K Upadhyaya; Pankaj Bansal; M. Nij Hawan and D K Sharma (2012): A study of factors affecting relapse in substance abuse. Indian J. L. Sci. 2(1):3135 .

Askar, A. \& El Didi, R. (2005), Relapse Attitude Questionnaire 100, Anglo Egyptian Library.

Beuster, J.T.R. \& Arnott, R. (2007): Predictors of treatment non-adherence in an inpatient substance abuse rehabilitation programme. Health SA, 12(4):53-68.

Broome, K.M., Simpson, D.D. \& Joe, G.W. (2002): The role of social support following short-term inpatient treatment. The American journal on addictions, 11:57-65.

Chang G, Martin KB, Tang M, Fleming JA (2016): Inpatient hospitalization for substance use disorders one year after residential rehabilitation: predictors among US veterans. Am J Drug Alcohol Abuse 42: 56-62.11. Gossop M, Stewart D, Browne N, Marsden J (2002) Factors associated.

Connors, G.J., Maisto, S.A. \& Donovan, D.M. (1996): Conceptualizations of relapse: a summary of psychological and psychobiological models. Addiction, 91:513. 
Hamdi E, Sabry N, Sedrak A, Khowailed A, Loza N.( 2016) Sociodemographic Indicators for Substance Use and Abuse in Egypt. J Addiction Prevention.;4(1): 8.

Hamdi E, Sabry N., Khoweiled, AEdwarda,A and E nabab, D. (2013) The National Addiction Research Program: prevalence of alcohol and substance use among women in Cairo Egyptian Journal of Psychiatry[online]. Vol. 34Pp155-163. [viewed 20 November 2017]. Available from( http://www.psychiatry-researcheg.com/texts/EJP/2013/9-

12/EgyptJPsychiatr3431555695977_154919.pdf.

Ibrahim, F. \& Kumar, N. (2009): Factors Effecting Drug Relapse in Malaysia: Empirical Evidence. Asian Social Science, 5(12):3743.

Iqbal, N (2009): Substance dependency: A hospital based Survey, Saudi Medical Journal, 2000, Vol. 21(1):51-57.

Marlatt, G.A. \& Witkiewitz, K. (2007): Relapse prevention for alcohol and drug problems. In Marlatt, G.A. \& Donovan, D.M. (Ed.) Relapse Prevention - Maintenance Strategies in the Treatment of Addictive Behaviours. $2^{\text {nd }}$ ed. New York: The Guildford Press.

Marlatt, G.A. (1996): Taxonomy of high-risk situations for alcohol relapses: evolution and development of a cognitive-behavioural model. Addiction, 91:37-49.

McPherson C, Boyne H, Waseem R (2017): Understanding the Factors that Impact Relapse Post-residential Addiction Treatment, a Six Month Follow-up from a Canadian Treatment Centre. J Alcohol Drug Depend 5: 268. doi:10.4172/23296488.1000268.
Mohamed N., (2009): Factors Influencing Relapse among Patients with Substances Abuse, Egyptian Journal of Health Care, $1^{\text {st }}$ edition, pp.31-40.

Perkinson, R.R. (2004): Treating alcoholism. New Jersey: John Wiley \& Sons.

Psychol Clin Psychiatry 6(6): 00381. DOI: 10.15406/jpcpy.2016.06.00381

Rimaz S, Mohseni S, Merghati Khoei ES, Dastoorpour M, Akbari F. Casecontrol (2013): study of factors influencing on drug abuse relapse in addicts referred to two recovery centers in Tehran. J School Public Health Inst Public Health Res.; 10(3):53-64.

Sampson, Beatrice Nyege, Frank, Maureen Dike and Nkamare Maureen, B., RobinsonBassey Grace, C. and Wokne-Eze Lazarus ( 2017): "Factors influencing relapse among substance abuse patients attending neuropsychiatric hospital rumuigbo port harcourt, Nigeria", International Journal of Development Research, 7, (11), 1698416989.

Strowig, A.B. (2000): Relapse determinants reported by men treated for alcohol addiction the prominence of depressed mood. Journal of Substance Abuse Treatment, 19:469-474.

Wechsberg. W.M., (2012): Promising international interventions and treatment for women who use and abuse drugs: Focusing on the issues through the In Women's Group. Substance Abuse and Rehabilitation, 3(1), 1-4.

Zywiak, W.H., Connors, G.J., Maisto, S.A. \& Westerberg, V.S. (1996): Relapse research and the reasons for drinking questionnaire: a factor analysis of Marlatt's relapse taxonomy. Addiction, 91:121-130. 